\title{
Violence Risk Assessment in Lithuania
}

\author{
Rita Žukauskiené $\dot{1}^{1^{*}}$, Alfredas Laurinavičius ${ }^{2}$ and Jay P Singh ${ }^{3}$ \\ ${ }^{1}$ Institute of Psychology, Mykolas Romeris University, Vilnius, Lithuania \\ ${ }^{2}$ Global Institute of Forensic Research, Reston, VA, USA \\ ${ }^{3}$ Faculty of Health Sciences, Molde University College, Molde, Norway \\ "Corresponding author: Rita Žukauskienè, PhD, Institute of Psychology, Mykolas Romeris University, Ateities St. 20, LT-08303 Vilnius, Lithuania, Tel: (3705)2714620; \\ Fax: (3705) 2714711; E-mail: rzukausk@mruni.eu
}

Received date: April 6, 2014; Accepted date: May 19, 2014; published date: May 31, 2014

Copyright: (c) 2014 Žukauskienè R, et al. This is an open-access article distributed under the terms of the Creative Commons Attribution License, which permits unrestricted use, distribution, and reproduction in any medium, provided the original author and source are credited.

\begin{abstract}
Evaluating the risk of violence and re-offending with recognized and validated instruments is a new practice in Baltic countries such as Lithuania. Actuarial assessment and structured professional judgment methods were developed in North American and Western European nations and have recently been adjusted to local settings for research and practice. The present manuscript reviews research, contemporary practice, and relevant policies regarding violence risk assessment in the Baltic region. Specifically, the focus will be on the implementation and patterns of use for risk assessment instruments in Lithuania. The correctional and forensic mental health systems of the country will be described, followed by an overview of government-supported risk assessment tools. The manuscript reviews Lithuanian research on these tools and offers directions for future research and practice.
\end{abstract}

Keywords: Violence; Risk assessment; Lithuania; Forensic; Crime

\section{Violence Risk Assessment in Lithuania}

The aim of the present report is to review the Lithuanian correctional and mental health systems and to describe the current clinical practise and research regarding violence risk assessment tools in the country. We hope that this review will provide an accessible resource for clinicians and policymakers and additional support to implement evidence-based risk assessment practices in Lithuania.

During the Soviet occupation of Lithuania, the Lithuanian penal enforcement system was integral to the Soviet Union's overall system and fell under the jurisdiction of the Ministry of the Interior. On 1 September 2000, while reforming the legal system, the Lithuanian penal enforcement system was transferred from the jurisdiction of the Ministry of the Interior to the Ministry of Justice. The Department of Correctional Affairs again became the Prison Department under the Ministry of Justice of the Republic of Lithuania, the official name it had during the interwar period of independent Lithuania.

Lithuania has the third highest number of prisoners in the EU, according to statistics from the Council of Europe. There are 14 penal institutions and a penal hospital within the Prison Department that enforce pre-trial detention sanctions and custodial sentences imposed by court. Penal institutions are classified into facilities for sentenced and pre-trial detainees, juveniles and adults, and separate facilities for some men and women. Penal institutions are also categorized by security level, where prisons have high security, correctional work colonies have normal security, and colony-settlements are semi-open. The correctional work colonies, which house approximately $90 \%$ of sentenced inmates, include three levels of regime: common, strengthened, and strict. The levels vary by the manner in which inmates are supervised and by the security intensity. The three institutions for young offenders, who are between 14 and 18 years of age, are called reformatory work colonies and use both common and strengthened regimes.

Lithuania has a detailed Penal Enforcement Code that specifies the following items: the type of correctional institutions and regimes, regime requirements, conditions for inmate work, type of reformatory work, conditions for general education and vocational training, legal status of sentenced people, material provision and medical care of inmates, grounds and procedures for disciplining inmates, measures to ensure the regime, and grounds and procedures for exemption from a sentence.

After the court imposes a custodial sentence, the court is also responsible for designating the type of institution (prison, correctional work or reformatory work colony, or correctional work colony settlement) and the regime (common, strengthened or strict). The Correctional Affairs Department decides which institution an inmate is assigned to after observing the inmate and administering a personality assessment. Inmates can be conditionally released from penal institutions if they can be further reformed without being isolated from the community, and if they can prove, by their model behavior and honest work, that they have been rehabilitated. This form of conditional release does not apply to extremely dangerous recidivists or to offenders who, after having been conditionally released, committed a new crime.

In 2003, the Minister of Justice approved the structure, principles, and forms of activities of psychological offices within penitentiary institutions. The psychological offices oversee many tasks: evaluating the convict's personality; training new prisoners for adaptation skills; encouraging the prisoners to participate in social rehabilitation and social skills training; surveying the psychological microclimate of different prisoner groups; surveying the needs, risk factors, and psychosocial situation of prisoners' personalities; preventing psychological crises, suicides, and intentional auto-aggression; providing personal psychological therapy; performing the role of mediator in cases of interpersonal conflicts between prisoners or 
Page 2 of 6

between a prisoner and staff; organizing and implementing programs for target prisoner groups; organizing the professional evaluation of individual cases, in cooperation with specialists from psychological offices of other penitentiary institutions; recommending individualized prisoner correction and social rehabilitation; recommending prisoner housing and transfer; preparing report on the prisoners' characteristics; and educating staff and prisoners about mental health. Psychological offices report to the Director's deputy responsible for social rehabilitation, whereas health care offices report directly to the Director. The psychological and health care offices cooperate because of the mutual goodwill principle.

According to Order No.1-1, issued on 6 January 2005 by the Director of the Central Prison Hospital, several new job responsibilities were given to social workers and senior specialists in the psychiatric group that care for patients within the Psychiatric Division of the Central Prison Hospital. Social workers were assigned to examine the relationship of patients with their family members, define which family member has a positive influence upon the patients, and assist the patients in maintaining this positive relationship. The additional functions delegated to psychologists include treating and correcting patients' behaviours, consulting on the patients' dependence diseases, and being involved in patients' religious ceremonies.

A psychiatrist (or general practitioner if no psychiatrist is present) evaluates the mental health of each new inmate and includes this information in the inmate's health history. The psychiatrist generally evaluates the inmate for any auto-aggression, drug or alcohol addiction, brain trauma, or central nervous system injury and diagnoses any mental disorders.

The general provisions of mental health care in Lithuania are defined in the Law on Mental Health Care in Lithuania. No data exist to objectively evaluate the quality of psychiatric care at prisons in Lithuania. It is possible that psychiatric care may not be the highest quality because of (a) the lack of staff, (b) the level of staff competence, or (c) the failure to create a system with quality supervision. The quality of psychiatric care in Lithuania has only recently become a topic of interest. The lack of trained mental health professionals at correctional facilities and the focus on security over treatment retards recovery, rehabilitation, and crime prevention. Only prisoners with a severe mental disability are not held accountable for their actions. In such cases, mandatory treatment is provided. However, prisoners diagnosed with a personality disorder, which is not treated as a severe mental disability, receive a simple custodial sentence that is usually served in a disciplinary group specific to the particular personality disorder. An inmate with a personality disorder may be confined to a penalty isolator in an Eastern European prison, whereas a similar inmate in a Western European prison may receive treatment for the personality disorder.
Forensic psychiatry in Lithuania is considered part of the health care system and directed by the Ministry of Health Care. Until 2002, prisoners with mental disorders who were subjected to coercive medical measures were treated in general mental hospitals. Housing patients in this manner did not allow for individual treatment programmes. No specially trained personnel existed in these hospitals to address prisoner resocialisation and reintegration into the public. Therefore, in 2002, all prisoners with mental disorders who were subjected to coercive medical measures were treated at Rokiškis psychiatric hospital (Juodkaite and Klimukiene) [1].

\section{Clinical Use of and Research on Violence Risk Assessment in Lithuania}

Forensic psychiatry in Eastern Europe, and in particular in the former Soviet Union, systematically used psychiatry for political purposes by declaring political and religious dissidents mentally ill [2-4]. After Lithuania joined the European Union, the forensic psychiatry system and prison system were reformed. Between 2004 and 2007, the Global Initiative on Psychiatry (GIP) implemented a project to reorganize forensic services in Lithuania. The goal was to deliver psychiatric treatment that adequately cared for patients and protected society from individuals with severe mental disorders who have committed a crime. Providing adequate care to patients within forensic psychiatry and protecting society are directly related the risk of future criminal offences [5].

In Lithuania, as in most post-Soviet states, the risk of a patient committing a future crime is primarily assessed by unstructured clinical judgement, where each clinician subjectively (and often implicitly) decides on the risk [5]. Within the past several years, however, risk assessment tools have been introduced into practice in Baltic countries, with unstructured assessments being the dominant form. In 2012, the Director General of the Prison Department under the Ministry of Justice of the Republic of Lithuania, Artūras Norkevičius, approved a list of validated forensic instruments to use for risk assessment. Approved actuarial instruments included the Offender Assessment System [6] and the Psychopathy Checklist: Screening Version [7]. Approved structured professional judgement (SPJ) tools included the Historical, Clinical, Risk Mangement-20 [8], the Spousal Assault Risk Assessment [9], the Sexual Violence Risk-20 [8], and the Brief Spousal Assault Form for the Evaluation of Risk [10]. Table 1 provides a list of the Lithuanian translations of these tools. Since their approval, these instruments have become widely used in the Lithuanian correctional system. HCR-20 [8] can also be used in the mental health system.

\begin{tabular}{|l|l|l|}
\hline Assessment & Original Reference & Lithuanian Translation \\
\hline OASys & Home Office [6] & $\begin{array}{l}\text { Teisèspažeidėjo } \\
\text { IvertinimoSistemaOASys }\end{array}$ \\
\hline PCL:SV1 & Hart et al. [7] & $\begin{array}{l}\text { Hare PCL:SV } \\
\text { Psichopatijosklausimynas: atrankosversija }\end{array}$ \\
\hline HCR-20 & Webster et al. [8] & HCR-20 \\
\hline
\end{tabular}


Page 3 of 6

\begin{tabular}{|l|l|l|}
\hline & & Smurtorizikosivertinimas \\
\hline SARA & Kropp et al.[9] & Prievarta tarp sutuoktiniu. \\
& & Rizikosivertinimovadovas \\
\hline SVR-20 & Boer et al. [8] & $\begin{array}{l}\text { SVR-20 } \\
\text { Seksualiniosmurto rizika-20 }\end{array}$ \\
\hline B-SAFER & Kropp\& Hart [10] & B-SAFER \\
& & Trumpasmurtošeimojejizikosivertinimo forma \\
\hline
\end{tabular}

Table 1: Lithuanian Translations of Validated Violence Risk Assessment Tools. Note: OASys=Offender Assessment System; PCL:SV=Psychopathy Checklist: Screening Version; HCR-20=Historical, Clinical, Risk Management-20; SARA = Spousal Assault Risk Assessment; SVR-20 = Sexual Violence Risk-20; B-SAFER=Brief Spousal Assault Form for the Evaluation of Risk.

Although the PCL:SV was not initially developed for violence risk assessment, survey evidence suggests that it is commonly used for this purpose internationally. Prior to the Lithuanian government approving the forensic instruments, a number of research studies explored the psychometric properties of the instruments [11-16]. We will review these studies in detail.

\section{OASys}

The Home Office, a ministerial government department in the United Kingdom, designed the OASys to assess the risk of offenders being reconvicted. The OASys is now viewed as an integral part of the National Offender Management Service (NOMS) of England and Wales. The instrument is composed of 84 items organised into 12 scales on the following topics: Offending information; Accommodation; Education, training and employability; financial management and income; Relationships; Lifestyle and associates; Drug misuse; Alcohol misuse; Emotional wellbeing; Thinking and behaviour; and Attitudes. The validity of the instrument was tested in three pilot studies and the normative sample of 757 offenders was used to obtain a probabilistic estimate of recidivism risk. The predictive validity of the OASys and its composite items was tested in three studies of Lithuanian offenders [12,13,16]. A total of 213 adult prisoners (nMale=166, nFemale=47), from 12 custodial settings, ready for conditional or automatic release were included in the study. One month prior to release, 23 psychologists, working in custodial settings, administered OASys to the prisoners. Prior to data collection, the psychologists were trained to use the OASys by members of the research team. The assessment integrated criminal files and semistructured interviews. The prisoners were followed for 12 months after release. A conviction registration database was used to determine whether these prisoners were reconvicted of a criminal offense.

Ustinavičiūtè et al. [12,13] found that the OASys and its subscales discriminated different groups of offenders. Offenders whose only conviction occurred during adolescence had lower scores for almost all items (except financial management and income, drug misuse, and attitudes) compared to those who reoffended in adulthood. The biggest difference was found in these subscales: Emotional wellbeing $(t=4.751, p<0.001)$, offending information $(t=4.428, p<0.001)$, lifestyle and associates $(\mathrm{t}=4.286, \mathrm{p}<0.001)$ [12]. Further analysis of the data revealed the criminogenictraits that differentiate first time offenders from recidivists: Offending information $(t=10.96, p<0.001)$, Lifestyle and associates $(\mathrm{t}=5.71, \mathrm{p}<0.001)$, and Education, training and employability $(\mathrm{t}=4.40, \mathrm{p}<0.001)$ [13].
Receiver operating characteristic (ROC) curve analyses were also conducted with the sample to examine the probability that a randomly-selected recidivist had a higher OASys score than a randomly-selected non-recidivist [17,18]. Item-level ROC analyses were also conducted using the area under the ROC curve (AUC). Ustinavičiūte et al. [16] found statistically significant AUCs $(\mathrm{p}<0.001)$ for the overall sample ( $A U C=0.72$ ), for male offenders ( $A U C=0.67$ ), and for female offenders (AUC $=0.86$ ). The most statistically significant $(\mathrm{p}<0.001)$ discriminative factors were Education, training and employability $(A U C=0.69$ ) for the overall sample; Poor financial management and low income $(\mathrm{AUC}=0.68)$ and Education, training and employability $(\mathrm{AUC}=0.67)$ for the male offenders; and Emotional wellbeing (AUC=0.87) for the female offenders. The findings of these three analyses suggest that OASysis a useful and scientifically proven tool to assess the risk of reoffending in Lithuania.

\section{PCL:SV}

The PCL:SVis a personality assessment developed by Hart et al. [7] that serves as a preliminary screening device for psychopathic traits in adults, as defined by the Psychopathy Checklist-Revised [19]. The PCL:SV is composed of 12 items derived from Cleckley's [20] operational definition of the psychopathic personality in his work, The Mask of Sanity. The PCL:SV uses data collected in a file review and a semi-structured interview. Each item can have a value of up to two points. The instrument's authors recommend a cut-off score of 13 as the threshold for possible psychopathy. Although the PCLSV was not initially developed to assess violence risk, survey evidence suggests that it is commonly used for this purpose internationally [21] and a metaanalysis has demonstrated its utility in this regard [22]. Given the lack of invariant structure and item functioning in the PCL:SV, a study was conducted in Lithuania to ensure that the PCL:SV did not perform differently as a function of jurisdiction and culture $[14,15]$. Participants were recruited from 12 correctional facilities operating in Lithuania. A total of 294 inmates were randomly selected for the study, out of a facility population of 4670 incarcerated males $(6.3 \%$ of population). Thirty-eight inmates refused to participate in the study. The remaining 257 inmates were assessed using semi-structured interviews and criminal file analysis. Data was collected by 20 psychologists, from the 12 facilities, trained to administer the PCLSV.

Data analysis revealed that the PCL:SV items have a high level of internal consistency (Cronbach's $\alpha=0.85$ ) [23] and the total scores $(\mathrm{M}=14.63, \mathrm{SD}=5.12)$ were consistent with data from North American and European offenders [24,25]. Convergent validity analyses found that higher PCL:SV scores were significantly associated with the 
following demographic factors that are conceptually related to psychopathy: Years of education, Age at time of first contact with police, Age at time of first conviction, History of psychiatric treatment, Offense while intoxicated, Number of convictions, Number of violent offenses, Total time spent in correctional institutions, and Number of stable jobs ( $>6$ months) [15]. Confirmatory factor analyses (CFA) compared the fit of the two-, three- and four-factor models of psychopathy to the Lithuanian sample [14]. The two-factor model was not supported, while three- and four-factor models provided an acceptable fit to Lithuanian data. The four-factor model showed significantly better fit compared to the two-factor model. The findings suggested that the construct of psychopathy, as measured by the PCL:SV in Lithuania can be generalized across cultures.

HCR-20: The second version of the HCR-20 was designed to assess the risk of violent behavior in forensic and general psychiatric patients. The instrument is composed of 20 items organized into three scales: historical factors, clinical factors, and risk management factors. The total HCR-20 score, out of a possible 40 points, is not directly used to calculate an individual's likelihood of offending. Rather, the administering clinician uses judgment to interpret the findings and place the individual into one of three risk categories: low, moderate, or high risk.

Česniene [26] investigated the predictive validity of the HCR-20 in Lithuania. Participants included 76 criminal male offenders from 4 correctional houses and 42 forensic psychiatric patients from Rokiškis psychiatric hospital (a total of 118 participants). Psychologists from the institutions $(n=7)$ retrospectively coded the instrument by using medical and criminal records files. The psychologists were trained to code the HCR-20 data. Data about reoffending were collected for 12 months after an offender's release from the correctional institution or hospital. Data about reoffending were obtained from an official database. The mean total HCR-20 score was $14.96(\mathrm{SD}=6.56)$, with a mean historical scales core of $8.42(\mathrm{SD}=3.61)$ out of 20 , clinical scale score of 2.57 ( $\mathrm{SD}=2.16)$ out of 10 , and risk management scale score of $3.89(\mathrm{SD}=2.55)$ out of 10 . When ROC curve analyses were conducted, the AUC was 0.72 for the historical scale, 0.69 for the clinical scale, and 0.58 for the risk management scale. These findings suggested that the predictive validity of the HCR-20 may be maximized in Lithuania when the instrument is used as designed, with risk factor information guiding clinical assessments rather than combining such information in an actuarial fashion.

\section{SARA and B-SAFER}

SARA and B-SAFER are risk assessment tools that use a structured assessment judgement to assess violence in a family context. The SARA was designed by Kropp et al. [9] and consists of 20 items organized into four scales: criminal history, psychosocial adjustment, spousal assault history, and alleged/current offense. Administrators can also include other information that may be relevant to the risk level of the individual being assessed. This case-specific information is combined with the total score to assist practitioners with placing individuals into one of three risk categories (low, moderate, or high risk). The SARA was condensed into a shorter risk assessment tool, the Brief Spousal Assault Form for the Assessment of Risk (B-SAFER).The B-SAFER is a 10-item risk management tool that focuses on the accused's history of intimate partner violence, as well as difficulties with psychological and social adjustment. Each item is evaluated twice, once for recent problems and once for past problems. The B-SAFER was developed for use by professionals within the criminal justice system, including law enforcement officers [10]. Both tools are approved for use by the Prison Department under the Ministry of Justice of the Republic of Lithuania. Žukauskienè and Laurinavičius [11] prospectively investigated the predictive validity of the B-SAFER in a sample of 113 women who had been assaulted by a spouse and were interviewed at women's crisis centres in Vilnius, Kaunas or Klaipeda, Lithuania. After each woman was interviewed, psychologists, social workers, and project manager' sin Vilnius and Kaunas coded the B-SAFER results. Each spouse was assigned to a low-, moderate- or high risk group. On the basis of the interviews with the women, 11 spouses were assigned to the low risk group, 38 to the moderate risk group, and 64 to the high risk group. The women were interviewed again after two months in the community. Recidivism was defined as physical assault or sexual coercion/injury between partners and measured by the revised Conflict Tactics Scale [27]. A stepwise regression analysis, using item-level SARA scores as the independent variables, identified the most significant predictors of recidivism as violent acts in the past, violent threats or thoughts in the past, and escalation in the past $\left(\mathrm{R}^{2}=0.50\right)$. A one-way ANOVA analysis investigating violence from an intimate partner during this 2-month period found significant differences between spouses categorised as low, moderate, and high risk. Women with spouses in the high risk category suffered from more acts of violence from their partner than women with spouses in lower risk categories, $\mathrm{F}(2,110)=47.03, \mathrm{p}<0.001$. Results suggested that the B-SAFER is a reliable instrument to discriminate between recidivists and non-recidivists in Lithuania.

\section{SVR-20}

Boer et al. designed the SVR-20 to predict future violence (including sexual violence) in sex offenders. Information acquired from criminal records, psychological reports, and collateral interviews is used to score the tool's 20 items, which are organised into three scales: psychosocial adjustment, sexual offenses, and future plans. Taking into consideration the total SVR-20 score and additional risk and protective factors not included on the instrument, the administering clinician places individuals into one of three risk categories: low, moderate, or high risk. To date, two studies on the SVR-20 have been published using Lithuanian samples [28,29].

Mitrauskas and Česnienè [28] investigated the validity of the SVR-20 using a sample of 119 male sex offenders from five correctional facilities. All convicts were incarcerated by the Lithuanian Ministry of Justice in 2008. In addition to the SVR-20, a10-item actuarial risk assessment tool, Static-99, was used. Psychologists with risk assessment training who were working in the correctional facilities coded the results. The mean total SVR-20 score was 37.13 (SD=6.58), with a mean psychosocial adjustment scale score of $19.83(\mathrm{SD}=4.02)$ out of 22 , a mean sexual offenses scale score of $13.60(\mathrm{SD}=3.31)$ out of 14 , and a mean future plans scale score of $3.59(\mathrm{SD}=1.50)$ out of 6 . Higher SVR-20 scores were positively associated with number of victims and negatively associated with age at first encounter with law enforcement, age at first conviction, age at first sex offence conviction, number of registered marriages, and number of official jobs. A oneway ANOVA analysis showed that individuals assigned to the high risk category had higher Static-99 scores than individuals assigned to the low risk category, $\mathrm{F}(2,116)=13.33, \mathrm{p}<0.001$. The relationships and ANOVA results support the validity of the SVR-20. Mitrauskas and Bandzevičienè [29] conducted a subsequent study with these participants and found that the risk factors included on the SVR-20 could differentiate between rapists $(n=80)$ and child molesters $(n=39)$. Although the differences in total score were not significant, child 
Page 5 of 6

molesters had higher scores for sexual deviance $(\mathrm{z}=4.20, \mathrm{p}<0.01)$, being abused as a child $(\mathrm{z}=2.20, \mathrm{p}<0.05)$, having a major mental illness $(\mathrm{z}=3.12, \quad \mathrm{p}<0.01)$, substance use problems $(\mathrm{z}=2.17, \mathrm{p}<0.05)$, relationship problems $(\mathrm{z}=2.39, \mathrm{p}<0.05)$, past nonsexual violent offenses $(\mathrm{z}=3.06, \mathrm{p}<0.01)$, past supervision failure $(\mathrm{z}=3.49, \mathrm{p}<0.01)$, subjecting victims to physical harm in sex offenses $(\mathrm{z}=2.223, \mathrm{p}<0.05)$, and escalation in frequency or severity of sex offenses $(\mathrm{z}=3.72, \mathrm{p}<0.01)$. Overall, findings from these analyses confirm the validity of the SVR-20 and support its use for risk assessment of sexual offenders.

\section{Risk Assessment Tool Use in Other Baltic Countries}

Compared to its neighbouring Baltic countries of Estonia and Latvia, Lithuania currently has the most state-of-the-art risk assessment approaches. In 2009, the Risk Matrix 2000 (RM2000; [30], an actuarial instrument composed of three static items, was introduced in the Estonian correctional system [31]. The Risk Matrix 2000 provides risk estimations for sexual recidivism and nonsexual violent recidivism perpetrated by sexual offenders. Since 2009, the Risk Matrix 2000 has been used to assess static risk factors of convicted sexual offenders when they are released on parole [31]. However, no empirical data is available on the psychometric properties of the RM2000 in the country. Further, no instrument incorporating dynamic risk factor into an assessment has been implemented [31]. Similarly, there is no empirical data on risk assessment instruments in Latvia. An exhaustive literature search found no evidence of structured approaches to risk assessment. In summary, Estonia and Latvia are just beginning to implement risk assessment instruments and Lithuania currently uses state-of-the-art risk assessment approaches.

\section{Future Directions for Risk Assessment in Lithuania}

Though there has been substantial use of violence risk assessments in Lithuania within the last decade, we see several directions for future research in this region. Each assessment tool could benefit from further studies. Inter-rater reliability analyses are needed for the OASys, PCL:SV, HCR-20, SARA, and SVR-20 tools to determine how much agreement exists between different analyses of the same individual.

Prospective predictive validity studies would be useful for the OASys, PCL:SV, HCR-20, SARA, and B-SAFER tools. In particular, we would like to know the predictive validity of the OASys for violent offending as the outcome. The B-SAFER needs a predictive validity study with discrimination and calibration validity assessed using final risk judgments as the independent variable and dichotomous recidivism as the dependent variable.

The OASys tool would benefit from a calibration study to look at the goodness-of-fit between expected recidivism estimates and observed recidivism estimates. In other words, the study should determine if the norms published by the Home Office are valid for Lithuania. A future study could examine the use of the PCL:SV to screen individuals eligible for full PCL-R testing and assess the predictive validity of both the PCL:SV and PCL-R. In addition to research, we see new opportunities to incorporate violence risk assessment in clinical practice in Lithuania. Education on violence risk assessment can occur in courses during graduate education and government-funded training sessions at custodial settings and hospitals. Lithuania's national psychological, psychiatric, and nursing organizations can adopt guidelines formally recommending that their members use the risk assessment tools in clinical settings.
An important component of violence risk assessment in Lithuania is the policy and legal statutes put forth by governmental bodies. To better align research, practice, and policy for violence risk assessment, the aforementioned tools should be required, rather than recommended, to make decisions about the care and fate of inmates in correctional facilities. In addition, the Ministry of Health and the Department of Corrections in Lithuania should use identical tools when assessing risk in forensic patients.

\section{References}

1. Juodkaite D, Klimukiene V. Concepts and Procedures - Lithuania.

2. Bloch S, Reddaway P (1997) Russia's Political Hospital, London, UK.

3. Bloch S, Reddaway P (1984) Soviet Psychiatric Abuse. London, UK.

4. Van Voren R (1989) Soviet Psychiatric Abuse in the Gorbachev Era. Amsterdam: International Association on the Political Use of Psychiatry, the Netherlands.

5. Klimukiene V (2009) Risk assessment in Post-Soviet countries. Mental Health Reforms.

6. Home Office (2006) Offender Assessment System (OASys) user manual, London, UK.

7. Hart SD, Cox D, Hare RD (1995) Psychopathy Checklist: Screening Version. Multi-Health Systems, Toronto, Canada.

8. Boer DP, Hart SD, Kropp PR, Webster CD (1997) Manual for the Sexual Violence Risk-20. Professional guidelines for assessing risk of sexual violence. Burnaby, BC: Simon Fraser University, Mental Health, Law, and Policy Institute, Canada.

9. Kropp PR, Hart SD, Webster CD, Eaves D (1999) Spousal Assault Risk Assessment guide (SARA). Multi-Health Systems, Toronto, Canada.

10. Kropp P R, Hart S D (2005) The development of the Brief Spousal Assault Form for the Evaluation of Risk (B-SAFER): A tool for criminal justice professionals. Department of Justice Canada.

11. Laurinavicius A, Žukauskiene R (2009) The assessment of repeated intimate partner violence risk using the B-SAFER method. Socialinis Darbas 8: 103-111.

12. Ustinaviciute L, Žukauskiene R, Laurinavicius A (2009) Re-offending risk factors for convicts in Lithuania: Analysis of the discrimination validity of the OASys method. SocialiniuMoksluStudijos 4: 339-356.

13. Ustinaviciute L, Laurinavicius A, Žukauskiene R, Bandzeviciene R (2010) Criminogenic risk factors for different groups of Lithuanian offenders.SocialiniuMoksluStudijos 4: 39-56.

14. Žukauskiene R, Laurinavicius A, Cesniene I (2010) Testing factorial structure and validity of the PCL:SV in Lithuanian prison population. Journal of Psychopathology \& Behavioral Assessment 32:363-372.

15. Laurinavicius A, Žukauskiene R, Cesniene I (2011) Psychometric characteristics of the Psychopathy Checklist: Screening Version in a sample of Lithuanian offenders. Socialinis Darbas 10:138-146.

16. Ustinaviciute L, Laurinavicius A, Žukauskiene R (2012) Evaluation of recidivism using the OASys: Prognostic validity using a sample of Lithuanian convicts. Lietuvos Psichologu Kongresas, Klaipeda, Lithuania.

17. Singh JP (2013) Predictive validity performance indicators in violence risk assessment: a methodological primer. Behav Sci Law 31: 8-22.

18. Singh JP, Desmarais SL, Van Dorn RA (2013) Measurement of predictive validity in violence risk assessment studies: a second-order systematic review. BehavSci Law 31: 55-73.

19. Hare RD (2003) The Hare Psychopathy Checklist-Revised (2nd edn) Multi-Health Systems, Toronto, Canada.

20. Cleckley H (1941) The mask of sanity. St. Louis: C.V. Mosby.

21. Singh JP (2013a) The International Risk Survey (IRiS) project: Perspectives on the practical application of violence risk assessment tools. The American Psychology-Law Society, Portland, OR. 
Citation: Žukauskiene R, Laurinavicius A, Singh JP (2014) Violence Risk Assessment in Lithuania. J Psychiatry 17: 127. doi: $10.4172 / 2378-5756.1000127$

Page 6 of 6

22. Leistico AM, Salekin RT, De Coster J, Rogers R (2008) A large-scale meta-analysis relating the hare measures of psychopathy to antisocial conduct. Law Hum Behav 32: 28-45.

23. George D, Mallery P (2003) SPSS for Windows step-by-step: A simple guide and reference. Boston: Allyn \& Bacon.

24. Wogan M, MacKenzie M (2007) An inmate classification system based on PCL:SV factor scores in a sample of prison inmates. Journal of Offender Rehabilitation 44: 25-42.

25. Douglas KS, Strand S, Belfrage H, Fransson G, Levander S (2005) Reliability and Validity Evaluation of the Psychopathy Checklist: Screening Version (PCL:SV) in Swedish correctional and forensic psychiatric samples. Assessment 12: 145-161.

26. Cesniene I (2010) Violence risk assessment in two forensic samples using the HCR-20 in Lithuania. European Psychiatry 25: 751.
27. Straus MA, Hamby SL, Boney-McCoy S, Sugarman DB (1996) The revised Conflict Tactics Scales (CTS2): Development and preliminary psychometric data. Journal of Family Issues 17: 283-316.

28. Mitrauskas M, Cesniene I (2011) The construct validity of the SVR-20 in Lithuanian sex offenders sample. 11th European Conference on Psychological Assessment, Riga, Latvia.

29. Mitrauskas M, Bandzeviciene R (2013) A comparative analysis of psychosocial risk factors for criminal sexual offenders. Socialinis Darbas 12: 175-185.

30. Thornton D, Mann R, Webster S, Blud L, Travers R, et al. (2003) Distinguishing and combining risks for sexual and violent recidivism. Ann N Y Acad Sci 989: 225-235.

31. Tamm K (2010) Sexual offender treatment in Estonia: The current situation and future perspective. Tallinn: Justiits Ministeerium. 